\title{
Pengaruh Teknik Relaksasi Otot Progresif Terhadap Penurunan Tekanan Darah Pada Pasien Hipertensi Di Puskesmas Mariat Kabupaten Sorong
}

\author{
Ade Supriatna ${ }^{1}$, Norma ${ }^{2}$ \\ ${ }^{1}$ Jurusan Keperawatan Politeknik Kesehatan Sorong \\ Email: normaepid@gmail.com
}

\begin{abstract}
Effect of Progressive Muscle Relaxation Technique on Decreasing Blood Pressure in Hypertensive Patients in Mariat Health Center, Sorong Regency. Hypertension is a disease that results from an increase in systolic and diastolic blood pressure consistently above 140/90 $\mathrm{mmHg}$. Hypertension is a factor that contributes to stroke deaths and factors that aggravate myocardial infarction (heart attack). The number of people with hypertension continues to increase along with the growing population, the world prevalence reaches $29.2 \%$ in men and $24 \%$ in women. This study was conducted with the aim to determine whether there is an effect of progressive muscle relaxation techniques on the reduction of blood pressure in hypertensive patients at the Mariat Health Center in Sorong Regency. In this study the researchers used the Quasi experimental Design design with a one-group pretest-posttest design approach (one pretest-posttest group). The population in this study were hypertensive patients who came to the Mariat Health Center in 2018 as many as 32 patients. While the research sample is a total population of 32 respondents. The results of the statistical test using the Paired Sample t-test obtained a value of p_value for systolic blood pressure 0,000 smaller than 0.05 and the value of $p_{-}$value for a diastolic blood pressure of 0,000 less than 0.05 . From the results of statistical tests show that there is an effect of progressive muscle relaxation techniques on blood pressure reduction in hypertensive patients at Mariat Health Center, Sorong Regency.
\end{abstract}

Keywords: Relaxation, Progressive Muscle, Hypertension

\begin{abstract}
Abstrak: Pengaruh Teknik Relaksasi Otot Progresif Terhadap Penurunan Tekanan Darah Pada Pasien Hipertensi Di Puskesmas Mariat Kabupaten Sorong. Hipertensi adalah penyakit yang terjadi akibat peningkatan tekanan darah sistolik dan diastolik dengan konsisten di atas 140/90 mmHg. Hipertensi merupakan faktor yang berkonstribusi terhadap kematian akibat stroke dan faktor yang memperberat infark miokard (serangan jantung). Jumlah penderita hipertensi terus meningkat seiring dengan jumlah penduduk yang membesar, prevalensi dunia mencapai $29,2 \%$ pada laki-laki dan $24 \%$ pada perempuan. Penelitian ini di lakukan dengan tujuan untuk mengetahui ada tidaknya pengaruh teknik relaksasi otot progresif terhadap penurunan tekanan darah pada pasien hipertensi di Puskesmas Mariat Kabupaten Sorong. Dalam penelitian ini peneliti menggunakan desain Quasi experimental Design dengan pendekatan one-Group Pretest-Posttest Design (Satu Kelompok Pretes-postes). Populasi dalam penelitian ini adalah pasien penderita hipertensi yang datang berobat di Puskesmas Mariat pada pahun 2018 sebanyak 32 pasien. Sedangkan sampel penelitian yaitu total populasi sebanyak 32 responden. Hasil uji statistik menggunakan uji Paired Sample t-test diperoleh nilai p_value untuk tekanan darah sistolik 0,000 lebih kecil dari 0,05 dan nilai p_value untuk tekanan darah diastolik 0,000 lebih kecil dari 0,05. Dari Hasil uji statistik menunjukan bahwa ada pengaruh teknik relaksasi otot progresif terhadap penururnan tekanan darah pada pasien hipertensi di Puskesmas Mariat Kabupaten Sorong.
\end{abstract}

Kata Kunci : Relaksasi, Otot Progresif, Hipertensi 


\section{PENDAHULUAN}

Data Global Status Report on Noncommunicable Disesases 2016 menyebutkan, $40 \%$ negara ekonomi berkembang memiliki penderita hipertensi, sedangkan negara maju hanya $35 \%$. Kawasan Afrika memegang posisi puncak penderita hipertensi sebanyak $46 \%$ dan di kawasan Asia Tenggara 36\% orang dewasa menderita hipertensi (Kompas, 2016). Di Indonesia hipertensi merupakan masalah kesehatan yang utama dengan prevalensi yang tinggi dengan berdasarkan hasil pengukuran pada umur $\geq 18$ tahun sebesar 25,8\% (Riset Kesehatan Dasar, 2013).

Kejadian hipertensi yang meningkat setiap tahun mengindikasikan bahwa hipertensi perlu dan harus segera diatasi. Pengobatan hipertensi terdiri dari terapi farmakologis dan non farmakologis. hipertensi karena biaya yang dikeluarkan untuk terapi farmakologis relatif mahal dan menimbulkan efek samping yang tidak diinginkan penderita, yaitu dapat memperburuk keadaan penyakit atau efek fatal lainnya (Susilo \& Wulandari, 2011).

Langkah awal pengobatan hipertensi non farmakologis adalah dengan menjalani pola hidup sehat, salah satunya dengan terapi komplementer yang menggunakan bahan-bahan alami yang ada disekitar kita, seperti relaksasi otot progresif, meditasi, aromaterapi, terapi herbal, terapi nutrisi. Terapi relaksasi memberikan individu mengontrol diri ketika terjadi rasa tidak nyaman atau nyeri (Susilo \& Wulandari, 2011).

Relaksasi otot progresif adalah teknik sistematis untuk mencapai keadaan relaksasi metode yang diterapkan melalui penerapan metode progresif dengan latihan bertahap dan berkesinambungan pada otot skeletal dengan cara menegangkan dan melemaskannya yang dapat mengembalikan perasaan otot sehingga otot menjadi rileks dan dapat digunakan sebagai pengobatan untuk menurunkan tekanan darah pada penderita hipertensi esensial (Ramba, dkk, 2015).

Berdasarkan survei pendahuluan di Puskesmas Mariat Kabupaten Sorong bahwa kunjungan penderita hipertensi tahun 2016 sebanyak 550 pasien rata-rata perbulannya 45 pasien sedangakn tahun 2017 sebanyak 565 pasien yang rata-rata perbulan sebanyak 47 pasien. Sementara data dari Prolanis (Program Pengelolaan Penyakit Kronis) Puskesmas Mariat bahwa tiap bulan pasien yang rutin berkunjung sebanyak 84 pasien. Dari 84 pasien tersebut yang Khusus menderita hypertensi sebanyak 32 pasien (Profil Puskesmas Mariat, 2017).

\section{METODE}

Desain penelitian ini adalah Quasi experimental Design dengan pendekatan oneGroup Pretest-Posttest Design ( Satu Kelompok Pretes-postes). Penelitian ini akan dilakukan di Wilayah Puskesmas Mariat Kabupaten Sorong dengan waktu pengambilan data selama 4 minggu pada Bulan Mei 2018. Sampel menggunakan total populasi yaitu sebanyak 32 responden. Data dianalisis dengan menggunakan Uji Pired Sample t-test. Berikut adalah prosedur penelitian :

1. Peneliti menjelsakan penelitian dengan menggunakan form penjelasan penelitia.

2. Setelah responden paham, kemudian diberikan informed consent untuk ditandatangani, apabila klien bersedia menjadi repsonden.

3. Pret tes : Responden diukur tekanan darahnya.

4. Intervensi : Responden diberi tindakan relaksasi progresif selama \pm 10 menit

5. Postest : kemudian responden diukur kembali tekanan darahnya.

\section{HASIL PENELITIAN}

Tabel 1.1. Distribusi Frekuensi Pre Test Pasien Hipertensi Berdasarkan Klasifikasi Hipertensi di Puskesmas Mariat Tahun 2018

\begin{tabular}{ccc}
\hline Klasifikasi & Frekuensi & Persen \\
\hline Derajat I & 12 & 37.5 \\
Derajat II & 8 & 25.0 \\
Derajat III & 12 & 37.5 \\
\hline Total & $\mathbf{3 2}$ & $\mathbf{1 0 0 . 0}$ \\
\hline
\end{tabular}

Berdasarkan tabel 1.1. di atas, terlihat bahwa data responden sebelum diberikan relaksasi otot progresif yang tergolong pada klasifikasi derajat I berjumlah 12 orang $(37,5 \%)$, derajat II sebanyak 8 orang $(25,0 \%)$ dan derajat III 12 orang $(37,5 \%)$. 
Tabel 1.2. Distribusi Frekuensi Post Test Pasien Hipertensi Berdasarkan Klasifikasi Hipertensi di Puskesmas Mariat Tahun 2018

\begin{tabular}{ccc}
\hline Klasifikasi & Frekuensi & Persen \\
\hline Optimal & 1 & 3.1 \\
Normal Tinggi & 1 & 3.1 \\
Derajat I & 15 & 46.9 \\
Derajat II & 10 & 31.2 \\
Derajat III & 5 & 15.6 \\
\hline Total & $\mathbf{3 2}$ & $\mathbf{1 0 0 . 0}$ \\
\hline
\end{tabular}

Berdasarkan tabel 2.2, di atas, data responden sesudah diberikan relaksasi otot progresif yang tergolong pada klasifikasi optimal sebanyak 1 orang $(3,1 \%)$, Normal Tinggi sebanyak 1 orang $(3,1 \%)$, derajat I sebanyak 15 orang $(46,9 \%)$, derajat II sebanyak 10 orang $(31,2 \%)$ dan derajat III sebanyak 5 orang $(15,6 \%)$.

Sebelum dilakukan uji bivariat, terlebih dahulu diuji normalitas data. Uji normalitas data dengan one sample Kolmogorov-Smirnov sebagai berikut :

Tabel 1.3. Uji Normalitas One-Sample Kolmogorov-Smirnov Test

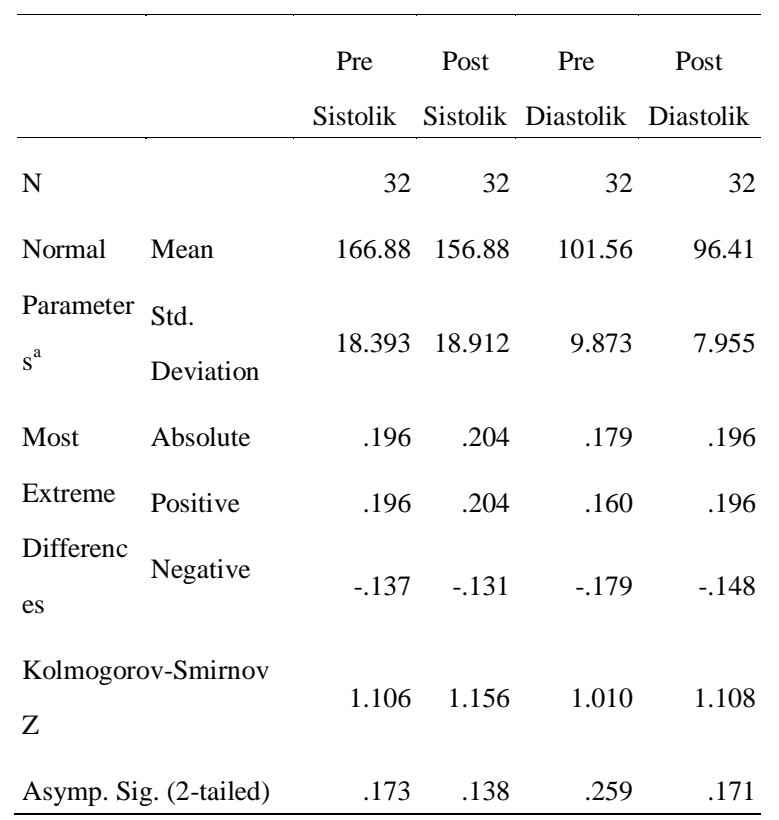

Berdasarkan table 1.3. di atas, diketahui bahwa nilai signifikansi sistolik sebelum diberikan relaksasi otot progresig sebesar 0,173 dan sesudah diberikan relaksasi otot progresif data sistolik 0,138 lebih besar dari pada 0,05 sehingga dapat disimpulkan bahwa data tersebut berdistribusi normal. Sedangkan nilai signifikansi untuk data diastolik sesudah diberikan relaksasi otot progresif sebesar 0,259 dan diastolik sesudah diberikan relaksasi otot progresif 0,171 , data tersebut lebih besar dari pada 0,05 sehingga dapat disimpulkan bahwa data tekanan darah diastolik, sebelum dan sesudah diberikan relaksasi otot progresif data berdistribusi normal.

Uji normalitas untuk data pre test sistolik dan post test sistolik, data pre test diastolik dan post test diastolik dari hasil analisis menyatakan bahwa data berdistribusi normal sehingga bisa dilakukan pengujian menggunakan uji Paired Sample t-test.

Tabel 1.4 Uji Bivariat Paired Samples Test

\begin{tabular}{|c|c|}
\hline Paired Differences & $\begin{array}{l}\text { Sig. } \\
\\
\\
\\
\text { tailed } \\
\text { df } \quad)\end{array}$ \\
\hline $\begin{array}{ccc} & \text { Std. } & \text { Std. } \\
& \text { Devi } & \text { Error } \\
\text { Mean } & \text { ation } & \text { Mean } \\
\end{array}$ & \\
\hline $\begin{array}{llll}\text { Pair } 1 & \text { Pre_Sistolik - } & & \\
& \text { Post_Sistolik } & & \\
& & & \\
\end{array}$ & $\begin{array}{lll}7.043 \quad 31 \quad .000 \\
\end{array}$ \\
\hline $\begin{array}{l}\text { Berdasarkan tabel } 1.4 \text { di } \\
\text { bahwa t-hitung adalah } 7.043 \\
\text { probabilitas atau nilai signifika } \\
0,000 \text {. Oleh karena nilai probabilit } \\
0,05 \text { maka H0 ditolak yang berarti } \\
\text { sistolik sebelum dan sesudah dib } \\
\text { relaksasi otot progresif adalah tid } \\
\text { berbeda nyata. Dalam tabel disertak } \\
\text { rata-rata sebesar } 10,000 \text { yaitu se } \\
\text { darah sistolik sebelum dan sesu }\end{array}$ & $\begin{array}{l}\text { atas, terlihat } \\
\text { dengan nilai } \\
\text { nsi (2-tailed) } \\
\text { as kurang dari } \\
\text { tekanan darah } \\
\text { erikan teknik } \\
\text { ak sama atau } \\
\text { can perbedaan } \\
\text { elisih tekanan } \\
\text { dah diberikan }\end{array}$ \\
\hline
\end{tabular}


teknik relaksasi otot progresif. Hal ini berarti ada pengaruh teknik relaksasi otot progresif terhadap tekanan penururnan tekanan darah pada pasien hipertensi di Puskesmas Mariat Kabupaten Sorong

\section{PEMBAHASAN}

Dari hasil uji Paired sample t-test terlihat perbedaan rata-rata yang signifikan antara tekanan darah sebelum sesudah diberikan teknik relakasasi progresif sehingga dapat menjawab tujuan penelitian ini apakah ada pengaruhnya terhadap tekanan darah ketika diberikan teknik relaksasi otot progresif.

Hasil penelitian ini relevan dengan penelitian yang dilakukan oleh Tri Murti (2011) tentang Perbedaan Tekanan Darah Pada Pasien Hipertensi Esensial sebelum dan sesudah Pemberian Relaksasi Otot Progresif Di RSUD Tugurejo Semarang. Hasil penelitian ini menunjukan bahwa terdapat perbedaan yang signifikan antara tekanan darah pasien sebelum dan sesudah diberikan Teknik relaksasi Otot Progresif. Selain itu dalam penelitian Rahmawati (2015) tentang Pengaruh Relaksasi Otot Progresif Terhadap Penurunan Tekanan Darah Pada Pasien Hipertensi Stage 1 Di Puskesmas Gongangrejo Karanganyar. Hasil peneliti an ini menunjukan bahwa ada perbedaan tekanan darah yang signifikan antara sebelum dan sesudah pemeberian teknik relaksasi otot progresif.

Relaksasi merupakan kebebasan mental dan fisik dari ketegangan dan stres (Potter \& Perry, 2009). Relaksasi merupakan serangkaian upaya untuk menegangkan dan mengendurkan otot-otot di tubuh untuk mencapai keadaan rileks. Teknik relaksasi progresif merupakan terapi non farmakologis yang mudah dilakukan untuk mengatasi gangguan tidur pada lansia (Asmadi, 2008). Relaksasi progresif merupakan kombinasi latihan pernapasan yang terkontrol dan rangkaian kontraksi serta relaksasi kelompok otot (Potter \& Perry, 2009).

Relaksasi otot progresif memodulasi respon rileks tubuh. Respon relaksasi ini terjadi melalui penurunan bermakna dari kebutuhan zat oksigen oleh tubuh, yang selanjutnya aliran darah akan lancar, neurotransmiter penenang akan dilepaskan, sistem saraf akan bekerja secara baik, otot-otot tubuh yang rileks menimbulkan perasaan tenang dan nyaman (Erliana et all, 2012). Latihan relaksasi yang dikombinasikan dengan latihan pernafasan yang terkontrol dan rangkaian kontraksi serta relaksasi kelompok otot, dapat menstimulasi respon relaksasi baik fisik maupun psikologis. Respon ini karena terangsangnya aktifitas sistem saraf otonom parasimpatis nuclei rafe yang terletak di bagian bawah pons dan medula oblongata sehingga mengakibatkan penurunan metabolisme tubuh, denyut nadi, tekanan darah, dan frekuensi pernafasan dan peningkatan sekresi serotnonin.

Brunner dan Suddarth (2002) mendefinisikan hipertensi sebagai tekanan darah persisten dimana tekanan sistoliknya diatas 140 $\mathrm{mmHg}$ dan tekanan diatolik diatas $90 \mathrm{mmHg}$. Pada populasi manula, hipertensi didefinisikan sebagai tekanan sistolik $160 \mathrm{mmHg}$ dan tekanan diastolik $90 \mathrm{mmHg}$. Hipertensi yang tidak diketahui penyebabnya didefinisikan sebagai hipertensi esensial. Beberapa penulis lebih memilih istilah hipertensi primer untuk membedakannya dengan hipertensi lain yang sekunder, karena sebab-sebab yang diketahui (Yogiantoro, 2009).

Menurut Sudoyo (2006), faktor-faktor resiko yang berperan dalam hipertensi adalah riwayat hipertensi atau kardiovaskuler pada pasien atau keluarga, umur, jenis kelamin, riwayat hiperlipidemia, diabetes melitus, kebiasaan merokok, pola makan dan asupan garam, kegemukan, intensitas olahraga, stres dan kepribadian. Sedangkan Yogiantoro (2009) menyebutkan bahwa faktor-faktor resiko yang mendorong timbulnya kenaikan tekanan darah adalah diet dan asupan garam, stres, ras, obesitas, merokok, genetik.

Tekanan darah merupakan salah satu parameter hemodinamik yang sederhana dan mudah dilakukan pengukurannya. Tekanan darah menggambarkan situasi hemodinamik seseorang saat itu. Hemodinamik adalah suatu keadaan dimana tekanan dan aliran darah dapat mempertahankan perfusi atau pertukaran zat di jaringan (Muttaqin, 2012). Tekanan darah diukur dalam satuan milimeter merkury $(\mathrm{mmHg})$ dan direkam dalam dua angka, yaitu tekanan sistolik (ketika jantung berdetak) terhadap tekanan diastolik (ketika jantung relaksasi). Tekanan darah sistolik merupakan jumlah tekanan terhadap dinding arteri setiap waktu jantung berkontraksi atau menekan darah keluar dari jantung. Tekanan diastolik merupakan jumlah tekanan dalam arteri sewaktu jantung beristirahat. Aksi pompa jantung memberikan tekanan yang mendorong darah melewati pembuluh-pembuluh. Setiap jantung berdenyut, darah dipompa keluar dari jantung kedalam pembuluh darah, yang membawa darah ke seluruh tubuh. Jumlah tekanan dalam sistem penting untuk mempertahankan pembuluh darah tetap terbuka (LeMone dan Burke, 2008). 


\section{SIMPULAN}

Hasil penelitian disimpulkan bahwa ada pengaruh teknik relaksasi otot progresif terhadap tekanan penururnan tekanan darah pada pasien hipertensi di Puskesmas Mariat Kabupaten Sorong.

\section{SARAN}

1. Penderita hipertensi diharapkan dapat menerapkan teknik relaksasi otot progresif pada kehidupan sehari-hari dengan waktu yang disarankan yaitu 2 sampai 4 kali tiap minggu sebelum tidur

2. Berdasarkan Hasil wawancara kepada responden rata-rata menyarankan agar tenaga kesehatan di wilayah setempat mensosialisasikan teknik relaksasi ini kepada penderita hipertensi di wilayah tersebut serta melatih pasien sesuai waktu yang disepakati.

3. Peneliti selanjutnya dapat melakukan penelitian dengan kasus yang sama hanya saja alat yang di gunakan menggunakan Rancangan Acak Lengkap, untuk melihat apakah terdapat pengaruh langsung terhadap tekanan darah, dengan melakukan beberapa kali pengulangan atau replikasi dengan 3 perlakuan yang berbeda sesuai dengan teori yang akurat.

\section{DAFTAR PUSTAKA}

Brunner and Suddarth. (2002). Buku Ajar Keperawatan Medikal Bedah, edisi 8 volume 2. Jakarta : EG

Erliana at all (2012). Studi Kasus.Cetakan I. Alih Bahasa : James Veldman. Jakarta :EGC

Kozier \& Erb, et al. ( 2009 ). Buku Ajar Praktik Keperawatan Klinis edisi 5. Jakarta : EGC.

Kusyanti. (2013). Keterampilan dan Prosedur Laboratorium. Keperawatan Dasar. Jakarta:EGC

LeMone dan Burke, (2008). Medicalsurgical nursing: critical thinking inclient care, 4th edition. New Jersey:Persone Prentice Hall.

Potter, P. A., \& Perry, A. G. (2009). Fundamentals of nursing: concept, process, and practice. 4/E (Terj. Yasmin Asih, et al). Jakarta: EGC.
Potter, Perry. (2010). Fundamental Of Nursing: Consep, Proses and Practice. Edisi 7. Vol. 3. Jakarta : EGC

Ramba, Gani, hendrik. 2015. Alat Analisis Data: Aplikasi Statistik untuk Penelitian Bidang Ekonomi dan Sosial. Yogyakarta: PT. Andi Offset.

Riset Kesehatan Dasar(Riskesdas). (2013). Badan Penelitian dan Pengembangan Kesehatan Kementerian RI tahun 2013. Diakses: 19 Oktober 2017, dari http:// www.depkes. go.id/ resources/download/general/Hasil\%20Ri skesdas\%202017.pdf

Sudoyo. 2006. Buku Ajar Ilmu Penyakit Dalam, jilid II, edisi V.Jakarta: Interna Publishing.

Susilo, Y., Wulandari, A. 2011. Cara Jitu Mengatasi

Penerbit Andi

Tri Murti (2011) Perbedaan tekanan darah pada pasien hipertensi esensial sebelum dan sesudah pemberian relaksasi otot progresif di RSUD Tugurejo Semarang. Diakses 24 oktober (2017) darihttp://180.250.144.150/ejournal/index.php/ilmukeperawatan/art icle/download/78/99

Udjianti, W. J. (2010). Keperawatan Kardiovaskuler Jakarta: Salemba Medika.

Yogiantoro, M., 2009. Hipertensi Esensial. In: Sudoyo, A.W., et al eds. Buku Ajar Ilmu Penyakit Dalam 5th ed. Jilid II. Jakarta: Interna Publishing, 1079-1085.

World Health Organization. Definisi Sehat WHO: WHO; 1947 [cited 201720 nopember]. Available from: www.who.int 
